\title{
Pattern of injuries in blunt trauma abdomen: A retrospective evaluation of imaging findings at a high-volume tertiary care trauma centre
}

\author{
Vikas Bhatia* $^{*}$, Suzanne Koshi, Varun Bansal, Uma Debi, Lokesh Singh, Manavjit Singh Sandhu \\ Department of Radio-Diagnosis, Nehru hospital, Postgraduate Institute of Medical Education and Research, Chandigarh , India
}

\author{
Received: 28 April 2021 \\ Accepted: 5 June 2021 \\ Published online: 17 June 2021 \\ *Corresponding author: \\ Vikas Bhatia, \\ Department of Radio-Diagnosis, \\ Nehru hospital, Postgraduate \\ Institute of Medical Education and \\ Research, Chandigarh, India \\ Email: drvikasbhatia@gmail.com \\ Competing interests: None. \\ Funding information: None. \\ Citation: Bhatia V, Koshi S, Bansal V, \\ Debi U, Singh L, Sandhu MS. Pattern \\ of injuries in blunt trauma abdomen: \\ A retrospective evaluation of \\ imaging findings at a high-volume \\ tertiary care trauma centre. Journal \\ of Emergency Practice and Trauma \\ 2022; 8(1): 13-18. doi: 10.34172/ \\ jept.2021.18
}

\begin{abstract}
Objective: Contrast-enhanced computed tomography (CECT) is the investigation of choice in trauma patients. The purpose of this study was to retrospectively evaluate the pattern, severity and association of abdominal injuries based on imaging at a high-volume tertiary trauma care centre.

Methods: Retrospective evaluation of the CT records of patients over a period of 5 years was done at our institute. A total of 1519 patients who had undergone contrast-enhanced abdominal CT at a 64-slice Multidetector CT for abdominal trauma were included in this study. Inclusion criteria were: 1) History of blunt abdominal trauma, 2) Patients who had undergone a biphasic CECT abdomen scan. Exclusion criteria were: 1) Patients with penetrating injury, 2) Patients with incomplete data set/records.

Results: Liver was the most common injured organ in both adult (38.8\%) and paediatric population (40.9\%). Significant higher incidence of mesenteric injury, bladder injury, spinal and rib fractures were seen in adult patients. Significant association of anorectal injuries $(P=0.003)$ and bladder/urethral injuries with pelvic fractures was also seen $(P<0.001)$.

Conclusion: Our study provided important insights about the pattern, severity and association between the various abdominal injuries based on imaging findings in a large patient population. Larger studies with incorporation of clinical outcome in such patients can help in formulating appropriate management strategies.
\end{abstract}

Keywords: Abdominal injury, Multidetector computed tomography, Blunt injury

\section{Introduction}

Early diagnosis and management of blunt abdominal trauma is important as the severity could be life threatening. Clinical examination alone is usually unreliable and radiology has become an indispensable tool in assessment of the extent and severity of trauma and henceforth appropriate management decisions (1).

Focussed assessment sonography in trauma (FAST) has largely replaced the diagnostic peritoneal lavage to diagnose intraperitoneal bleed in most of the cases (2). Although an easy to perform and reliable technique, FAST has some inherent limitations in obese patients, patients with ileus, operator dependent, limitations in grading the injury and evaluation of bowel/vascular injuries. It can also miss up to one fourth of the abdominal injuries (3).

CT is the gold standard investigation in evaluation of abdominal trauma with its multiplanar capability and rapid acquisition. It can clearly delineate the grade of injury, presence of bowel injury, presence of diaphragmatic or vascular injury and better assessment of retroperitoneal structures $(4,5)$.

Previous studies have demonstrated superiority of CT over FAST in traumatic abdominal organ injuries (6-8).

Former studies have also correlated the pattern of abdominal organ injuries with vascular injuries (9), spinal fractures (10) and pelvic fractures (11).

The purpose of this study was to evaluate the distribution, pattern, severity and association of abdominal injuries based on imaging assessment.

Methods

Retrospective evaluation of the CT records of patients with blunt abdominal trauma over a period of 5 years was done after taking the PGIMER Departmental ethical committee approval (ID: RDG/EC/Pub/139). A total of 1519 subjects who had undergone contrast-enhanced biphasic abdominal CT at a 64-slice MDCT for abdominal trauma were included in this study (Figure 1).

Inclusion criteria were: 1) Patients with blunt abdominal trauma, and 2) Patients who had undergone a biphasic CT scan abdomen.

Exclusion criteria were: 1) patients with penetrating injury, and

2) Patients with incomplete records. 


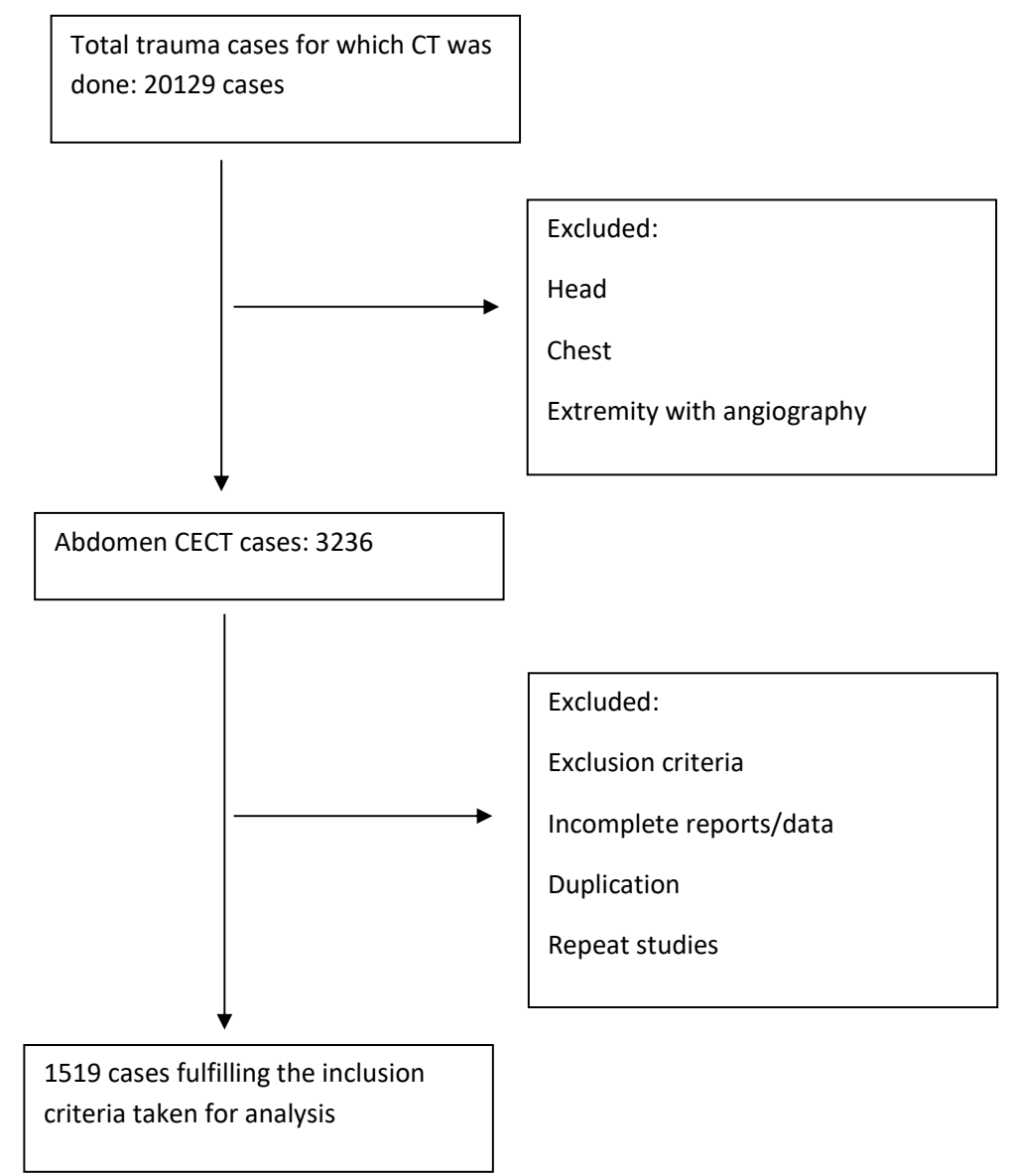

Figure 1. Flow chart of the study.

Demographic details of the patients were obtained from the clinical and radiological database of Emergency Radiology section. Contrast-enhanced computed tomography (CECT) scans were acquired on multidetector-row CT scanner (64 ACT, GE Healthcare). CT scans were performed after 25 seconds (arterial phase) and 65-70 seconds (venous phase) following intravenous injection of 80-100 mL of non-ionic contrast (Omnipaque ${ }^{\oplus}$ $300 \mathrm{mg} / \mathrm{mL}$, GE Healthcare). The scan parameters were tube current: $300 \mathrm{mAs}$; voltage: $120 \mathrm{kVp}$; pitch : 0.993; field of view: $350 \mathrm{~mm}$ and slice thickness: $1 \mathrm{~mm}$. The entire abdomen was scanned from domes of diaphragm to pubic symphysis. Delayed urographic phase (5-10 min) or CT cystograms (Retrograde catheter injection of $300 \mathrm{~mL}$ diluted contrast) were acquired in all cases of renal injuries or bladder injuries. The reports of these examinations were evaluated by two experienced radiologists (one consultant with over 10 years of experience and a senior fellow resident with 4 years of experience) and were scrutinised to identify the organ injuries and their grades along with other associated features such as fractures and vascular injuries.

The grades were based on the 2018 revision of the American Association for the Surgery of Trauma guidelines for liver, spleen, kidneys, pancreas and bladder. Bowel injuries were classified as contusions (wall thickening and haematoma) or perforations (demonstrable rent/ active contrast extravasations/pneumoperitoneum and pneumoretroperitoneum). The adrenal injury, urethral injuries, spinal and pelvic fractures were reported as present or absent without classification into subtypes. Mesenteric injury was reported as present if there was focal mesenteric fat stranding, mesenteric extravasation or mesenteric haematomas. Vascular injuries were classified into pseudoaneurysms, active contrast extravasation, arterial thrombosis, venous thrombosis and arteriovenous fistulas.

Continuous data were given as mean \pm SD and range. The significance of association between the subsets was evaluated using the Chi-square test. All statistical tests were two-sided and performed at a significance level of $\alpha=0.05$. Analyses were conducted using Statistical Package for the Social Sciences (SPSS) for Windows (version 17.0; SPSS Inc., Chicago, IL, USA).

\section{Results}

A total of 1519 patients who had undergone CECT abdomen for blunt trauma abdomen were included in the study. Demographic information of the study population is summarised in Table 1. The mean age of patients was 
$29.6 \pm 16$ years. Table 2 summarises the location, extent and demographic distribution of the injuries. Table 3 shows the pattern of vascular injuries. No significant

Table 1. Demographic information of the patients

\begin{tabular}{lc}
\hline Parameter & Number (\%) \\
\hline Gender & $1252(82.4)$ \\
Male & $267(17.6)$ \\
Female & \\
Paediatric $(\leq 18$ y) & $345(22.7)$ \\
Yes & $1174(77.3)$ \\
No & $1443(95)$ \\
FAST & $76(5)$ \\
Positive & \\
Negative/Inconclusive & $1432(94.3)$ \\
Mode of injury & $68(4.4)$ \\
RTA & $19(1.3)$ \\
\hline Fall from height & \\
Assault with blunt weapon &
\end{tabular}

association with mode of injury and specific organ injury was seen. Overall, the most common organ to be injured was the liver (39.2\%) followed by spleen (25.4\%), kidneys (13.6\%), adrenals (13.7\%), bowel (7.2\%), pancreas (5.5\%), bladder (3.3\%), and urethra (0.4\%), respectively. Grade III injuries were the most common in liver (30.5\%) (Figure 2), spleen (31.3\%) (Figure 3) and kidneys (33.6\% right, and $34 \%$ left). Grade 1 injuries $(38.1 \%)$ were the commonest in pancreas. Overall Grade V injuries were the least commonly encountered in all these organs. Mesenteric injuries were noted in 35 cases (2.3\%). The bladder injuries included 6 contusions, 20 intraperitoneal (IP) ruptures, 23 extra peritoneal (EP) ruptures and 1 combined $(\mathrm{EP}+\mathrm{IP})$ rupture (Figure 4). There was no significant difference in the frequency of organ/mesenteric involvement between males and females. Spinal fractures were recorded in 199 (13.1\%) of the patients. No significant association with other visceral injuries was noted. The most commonly injured organ in paediatric population was liver (40.9\%) with grade III injuries. Mesenteric injuries $(P=0.007)$, bladder injuries $(P=0.005)$ and spinal and rib fractures $(P<0.001)$ were significantly lower in the paediatric group

Table 2. Location, extent and demographic distribution of the injuries

\begin{tabular}{|c|c|c|c|c|c|}
\hline Site of injury & $\begin{array}{c}\text { Number of subjects } \\
\text { No. }(\%)\end{array}$ & $\begin{array}{c}\text { Male } \\
\text { No. }(\%)\end{array}$ & $\begin{array}{l}\text { Female } \\
\text { No. }(\%)\end{array}$ & $\begin{array}{l}\text { Pediatric } \\
\text { No. }(\%)\end{array}$ & $P$ value \\
\hline Liver & $596(39.2 \%)$ & $481(80.7 \%)$ & $115(19.3 \%)$ & $141(23.7 \%)$ & 0.26 \\
\hline Grade (I/II/III/IV/V/VI) & $(80 / 126 / 182 / 136 / 71 / 1)$ & $(65 / 97 / 148 / 111 / 59 / 1)$ & $(15 / 29 / 34 / 25 / 12 / 0)$ & $(16 / 31 / 43 / 33 / 18 / 0)$ & \\
\hline Spleen & $386(25.4 \%)$ & $321(83.1 \%)$ & $65(16.9 \%)$ & $80(20.7 \%)$ & 0.15 \\
\hline Grade (I/II/III/IV/V/VI) & $(63 / 117 / 121 / 64 / 21)$ & (49/101/103/51/17) & $(14 / 16 / 18 / 13 / 4)$ & $(8 / 17 / 27 / 20 / 8)$ & \\
\hline Pancreas & $84(5.5 \%)$ & $74(88.1 \%)$ & $10(11.9 \%)$ & $13(15.4 \%)$ & 0.109 \\
\hline Grade (I/II/III/IV/V) & $(32 / 17 / 26 / 8 / 1)$ & $(29 / 16 / 21 / 7 / 1)$ & $(3 / 1 / 5 / 1 / 0)$ & $(4 / 3 / 5 / 1 / 0)$ & \\
\hline \multicolumn{6}{|l|}{ Kidneys } \\
\hline Right & $125(8.2 \%)$ & $99(79.2 \%)$ & $26(20.8 \%)$ & $32(25.6 \%)$ & 0.241 \\
\hline Grade (I/II/III/IV/V) & $(34 / 22 / 42 / 14 / 13)$ & $(26 / 17 / 34 / 11 / 11)$ & $(8 / 5 / 8 / 3 / 2)$ & $(8 / 6 / 8 / 5 / 5)$ & \\
\hline Left & $97(6.4 \%)$ & $81(83.5 \%)$ & $16(16.5 \%)$ & $23(23.7 \%)$ & 0.445 \\
\hline Grade (I/II/III/IV/V) & $(23 / 18 / 33 / 17 / 6)$ & $(16 / 16 / 29 / 14 / 6)$ & $(7 / 2 / 4 / 3 / 0)$ & $(5 / 3 / 6 / 6 / 3)$ & \\
\hline Adrenals & $209(13.7 \%)$ & $175(83.7 \%)$ & $34(16.3 \%)$ & $37(17.7 \%)$ & 0.38 \\
\hline Small Bowel & $97(6.3 \%)$ & $87(89.6 \%)$ & $10(10.4 \%)$ & $17(17.5 \%)$ & 0.214 \\
\hline Type (contusion/perforation) & $(75 / 22)$ & $(66 / 21)$ & $(9 / 1)$ & $(13 / 4)$ & \\
\hline Large bowel & $13(0.8 \%)$ & $11(84.6 \%)$ & $2(15.4 \%)$ & $2(15.3 \%)$ & 0.27 \\
\hline Type (contusion/perforation) & $(8 / 5)$ & $(7 / 4)$ & $(1 / 1)$ & $(2 / 0)$ & \\
\hline Rectum and anal canal & $4(0.3 \%)$ & $4(100 \%)$ & $0(0 \%)$ & $2(50 \%)$ & 0.165 \\
\hline Mesentery & $35(2.3 \%)$ & $33(94.2 \%)$ & $2(5.8 \%)$ & $2(5.7 \%)$ & 0.007 \\
\hline Urinary Bladder & $50(3.3 \%)$ & $42(84 \%)$ & $8(16 \%)$ & $4(8 \%)$ & 0.005 \\
\hline Type (contusion/IP/EP/IP + EP) & $(6 / 20 / 23 / 1)$ & $(4 / 16 / 22 / 0)$ & $(2 / 4 / 1 / 1)$ & $(1 / 2 / 1 / 0)$ & \\
\hline Urethra & $7(0.5 \%)$ & $7(100 \%)$ & $0(0 \%)$ & $2(28.5 \%)$ & 0.497 \\
\hline Spine fracture & $199(13.1 \%)$ & $161(80.9 \%)$ & $38(19.1 \%)$ & $14(7 \%)$ & $<0.001$ \\
\hline Pelvic fracture & $343(22.6 \%)$ & $281(81.9 \%)$ & $62(19.1 \%)$ & $47(13.7 \%)$ & $<0.001$ \\
\hline Rib Fracture & $331(21.8 \%)$ & $284(85.8 \%)$ & $47(14.2 \%)$ & $25(7.5 \%)$ & $<0.001$ \\
\hline Diaphragmatic hernia & $9(0.6 \%)$ & $8(88.9 \%)$ & $1(11.1 \%)$ & $0(0 \%)$ & 0.098 \\
\hline
\end{tabular}


Table 3. Pattern and distribution of the vascular injuries

\begin{tabular}{|c|c|c|c|c|c|}
\hline Site of injury & $\begin{array}{c}\text { Number of subjects } \\
\text { No. }(\%)\end{array}$ & $\begin{array}{c}\text { Male } \\
\text { No. }(\%)\end{array}$ & $\begin{array}{l}\text { Female } \\
\text { No. }(\%)\end{array}$ & $\begin{array}{c}\text { Paediatric } \\
\text { No. }(\%)\end{array}$ & $P$ value \\
\hline Vascular injury & $110(7.2)$ & $86(78.1)$ & $24(21.9)$ & $30(27.7)$ & 0.108 \\
\hline Pseudoaneurysm & $39(2.6)$ & $30(76.9)$ & $9(23.1)$ & $6(15.3)$ & 0.182 \\
\hline Arterial thrombosis & $13(0.9)$ & $9(69.2)$ & $4(30.8)$ & $6(46.1)$ & 0.052 \\
\hline Active arterial contrast extravasation & $30(2)$ & $25(83.3)$ & $5(16.7)$ & $7(23.3)$ & 0.54 \\
\hline Venous thrombosis & $33(2.2)$ & $27(81.8)$ & $6(18.2)$ & $9(27.2)$ & 0.326 \\
\hline Arterial-Venous fistula & $5(0.3)$ & $5(100)$ & $0(0)$ & $1(20)$ & 0.681 \\
\hline
\end{tabular}

versus the adult group (Table 2). No significant difference between pattern of vascular injuries in adult and pediatric population was seen (Table 3 ). Pelvic fractures were noted in $343(22.6 \%)$ of individuals. Patients with rectal/anal injuries and bladder/urethral injuries had a significant association with pelvic fractures $(P=0.003, P<0.001$, respectively) (Table 4). No association of bladder/ bowel injury to spinal fractures was seen. No significant association of vascular injury with any other specific organ injury or fractures was observed. Hemoperitoneum was seen in $1392(91.6 \%)$ cases. Twenty-seven (1.7\%) patients had shown abdominal organ injury in the absence of hemoperitoneum.

\section{Discussion}

We conducted a large retrospective analysis of imaging findings in blunt trauma abdomen patients. A detailed analysis of demographic distribution, pattern and grading of injuries as well as association between the various injuries were performed. Injuries were more commonly seen in males $(P<0.0001)$ as noted in previous studies $(12,13)$. No significant association between sex distribution and organ injuries was seen. Liver was the most common organ injured in both adult (38.8\%) and paediatric population (40.9\%) in our study group. Previous studies have reported spleen(12) as well as liver(13-15) to be the most common injured organ in blunt abdominal trauma. Our study found Grade III to be the commonest injury in liver, spleen and kidneys whereas grade I was the commonest in pancreas. Previous research have shown grade II in spleen and liver and grade I/II in kidneys to be the most frequent injury (13).

We also found a significant higher incidence of mesenteric injury, bladder injury and spinal fractures in adults as compared to paediatric population. We could not find any studies comparing these injuries between adult and paediatric population. No association of spinal

Table 4. Relationship between spinal/pelvic fractures and bladder/bowel injuries

\begin{tabular}{lcc}
\hline & Bladder/urethral injury & Rectal/anal injuries \\
\hline Pelvic fractures & $43(12.5 \%)$ & $5(1.2 \%)$ \\
& $P<0.001$ & $P=0.03$ \\
Spinal fractures & $12(6 \%)$ & $1(0.5 \%)$ \\
& $P=0.023$ & $P=0.54$ \\
\hline
\end{tabular}

fractures with other visceral injuries was observed in our study. This finding is consistent with the previous study conducted by Rabinovici et al (16).

There was significant association of anorectal injuries $(P=0.003)$ and bladder/urethral injuries with pelvic fractures $(P<0.001)$. Previous studies have also shown significant association of pelvic fractures with bladder urethral, small bowel and liver injuries (17). We could not find any significant association of pelvic fractures

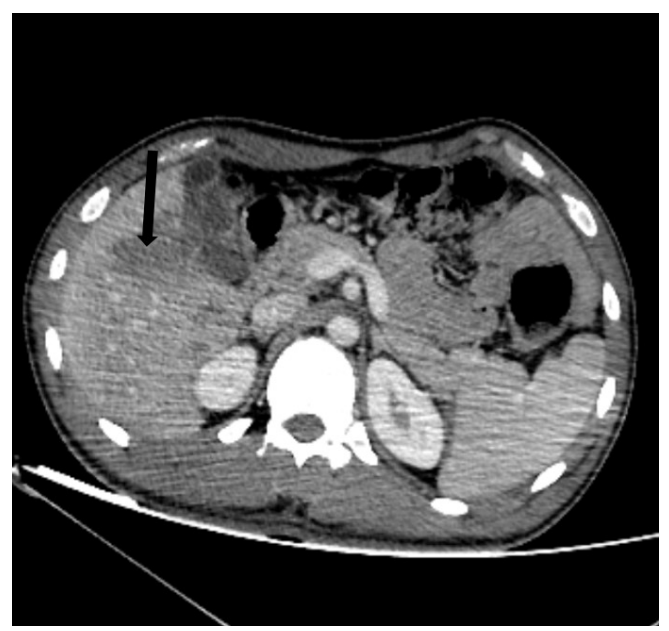

Figure 2. A 48-year-old male patient with road traffic accident. CECT abdomen venous phase image showing a laceration $>3 \mathrm{~cm}$ in segment 5 of liver (black arrow) s/o grade III hepatic injury.

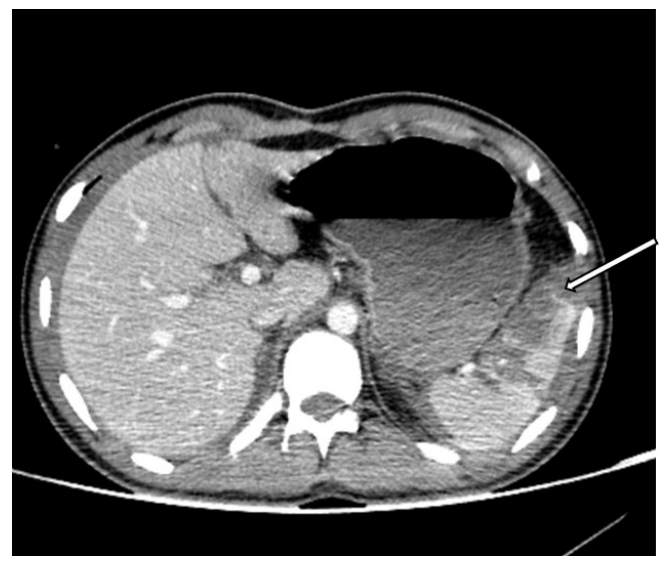

Figure 3. A 50-year-old male patient with road traffic accident. CECT abdomen venous phase image showing a laceration $>3 \mathrm{~cm}$ (white arrow) subcapsular hematoma s/o grade III splenic injury. 


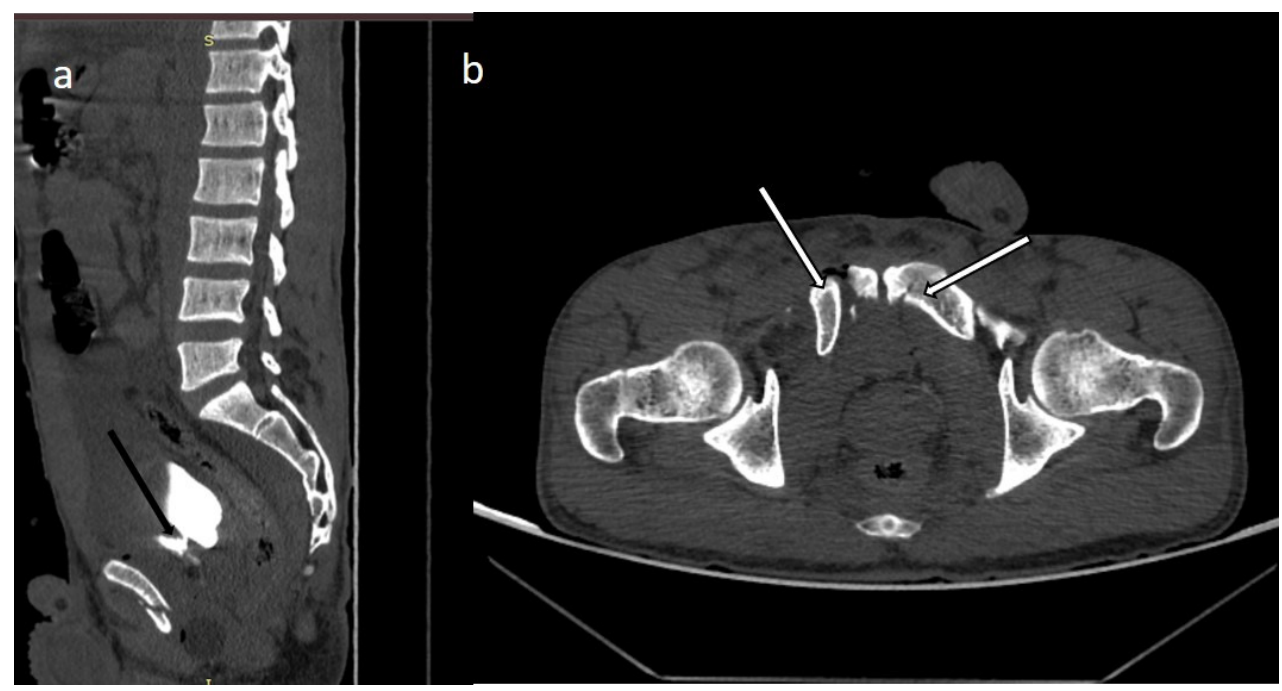

Figure 4. (a) A 40-year-old male patient with delayed contrast images showing rent in bladder neck and extraperitoneal contrast extravasation (black arrow). (b) Multiple pelvic fractures are seen involving inferior pubic rami and acetabulum (white arrow).

with small bowel or liver injuries. Vascular injuries were encountered in 110 patients (7.2\%). Previous studies have also shown up to $6 \%$ incidence of active haemorrhage (12). No significant association of vascular injury with age, gender or other specific organ injury or fractures was seen in our study. Some studies have not found any association between vascular injury and pelvic fractures whereas others have shown up to $3.5 \%$ of cases showing associated blunt iliac artery injury $(18,19)$. We also found that 27 (1.7\%) cases had abdominal organ injury in the absence of hemoperitoneum. CT provides important information for adequate management of trauma patients and has become the cornerstone for early diagnosis. However, good clinical assessment such as implementation of clinical prediction rule has been suggested to reduce unnecessary CT examination in trauma patients (20).

There are multiple limitations in our study. The data were retrospectively obtained from the radiology records of our department. The data for active management and follow up of these patients were not available, thus information about the outcome and prognostic value of these findings cannot be commented. Active contrast extravasation or demonstrable rent in bowel wall were considered as signs of bowel perforation, however a follow up is not available and some of the cases with sealed/delayed perforation may have not been included in the data. Vascular injuries were described based on typical imaging findings. However, a follow up surgical and endovascular findings were not included in this study. Detailed analysis or classification of various fractures was not included which may have important clinical implication.

\section{Conclusion}

We have presented a large dataset of imaging findings in blunt trauma abdomen patients. Association between pattern, severity and association of injuries in blunt trauma abdomen was assessed in the present study.

\section{Authors' contributions}

VB, SK, VB, LS contributed to the study design, data acquisition, and revision of the study. VB and SK contributed to statistical analysis and study revision. VB, UD and MS contributed to literature review, final approval and study revision. All authors contributed to data retrieval and image analysis.

\section{Ethical issues}

PGIMER Departmental Ethical Committee approved the study (Approval ID: RDG/EC/Pub/139).

\section{References}

1. Pinto F, Bode PJ, Tonerini M, Orsitto E. The role of the radiologist in the management of politrauma patients. Eur J Radiol 2006; 59(3): 315-6. doi: 10.1016/j.ejrad.2006.04.021.

2. Radwan MM, Abu-Zidan FM. Focussed Assessment Sonograph Trauma (FAST) and CT scan in blunt abdominal trauma: surgeon's perspective. Afr Health Sci 2006; 6(3): 187-90. doi: 10.5555/afhs.2006.6.3.187.

3. Stengel D, Bauwens K, Sehouli J, Porzsolt F, Rademacher G, Mutze S, et al. Systematic review and meta-analysis of emergency ultrasonography for blunt abdominal trauma. Br J Surg 2001; 88(7): 901-12. doi: 10.1046/j.00071323.2001.01777.x.

4. Hamilton JD, Kumaravel M, Censullo ML, Cohen AM, Kievlan DS, West OC. Multidetector CT evaluation of active extravasation in blunt abdominal and pelvic trauma patients. Radiographics 2008; 28(6): 1603-16. doi: 10.1148/ rg.286085522.

5. Elton C, Riaz AA, Young N, Schamschula R, Papadopoulos B, Malka V. Accuracy of computed tomography in the detection of blunt bowel and mesenteric injuries. Br J Surg 2005; 92(8): 1024-8. doi: 10.1002/bjs.4931.

6. Talari H, Moussavi N, Abedzadeh-Kalahroudi M, Atoof F, Abedini A. Correlation between intra-abdominal free fluid and solid organ injury in blunt abdominal trauma. Arch 
Trauma Res 2015; 4(3): e29184. doi: 10.5812/atr.29184.

7. Natarajan B, Gupta PK, Cemaj S, Sorensen M, Hatzoudis GI, Forse RA. FAST scan: is it worth doing in hemodynamically stable blunt trauma patients? Surgery 2010; 148(4): 695700. doi: 10.1016/j.surg.2010.07.032.

8. Lee BC, Ormsby EL, McGahan JP, Melendres GM, Richards JR. The utility of sonography for the triage of blunt abdominal trauma patients to exploratory laparotomy. AJR Am J Roentgenol 2007; 188(2): 415-21. doi: 10.2214/ ajr.05.2100.

9. Yasuhara H, Naka S, Kuroda T, Wada N. Blunt thoracic and abdominal vascular trauma and organ injury caused by road traffic accident. Eur J Vasc Endovasc Surg 2000; 20(6): 517-22. doi: 10.1053/ejvs.2000.1235.

10. Beaunoyer M, St-Vil D, Lallier M, Blanchard H. Abdominal injuries associated with thoraco-lumbar fractures after motor vehicle collision. J Pediatr Surg 2001; 36(5): 760-2. doi: 10.1053/jpsu.2001.22954.

11. Kwon HM, Kim SH, Hong JS, Choi WJ, Ahn R, Hong ES. Abdominal solid organ injury in trauma patients with pelvic bone fractures. Ulus Travma Acil Cerrahi Derg 2014; 20(2): 113-9. doi: 10.5505/tjtes.2014.72698.

12. Hamidi MI, Aldaoud KM, Qtaish I. The role of computed tomography in blunt abdominal trauma. Sultan Qaboos Univ Med J 2007; 7(1): 41-6.

13. El Wakeel AM, Habib RM, Ali AN. Role of CT in evaluation of blunt abdominal trauma. Int J Med Imaging 2015; 3(5): 89-93. doi: 10.11648/j.ijmi.20150305.11.

14. Clancy TV, Gary Maxwell J, Covington DL, Brinker CC, Blackman D. A statewide analysis of level I and II trauma centers for patients with major injuries. J Trauma 2001; 51(2): 346-51. doi: 10.1097/00005373-200108000-00021.

15. Matthes G, Stengel D, Seifert J, Rademacher G, Mutze S, Ekkernkamp A. Blunt liver injuries in polytrauma: results from a cohort study with the regular use of whole-body helical computed tomography. World J Surg 2003; 27(10): 1124-30. doi: 10.1007/s00268-003-6981-0.

16. Rabinovici R, Ovadia P, Mathiak G, Abdullah F. Abdominal injuries associated with lumbar spine fractures in blunt trauma. Injury 1999; 30(7): 471-4. doi: 10.1016/s00201383(99)00134-5.

17. Demetriades D, Karaiskakis M, Toutouzas K, Alo K, Velmahos G, Chan L. Pelvic fractures: epidemiology and predictors of associated abdominal injuries and outcomes. J Am Coll Surg 2002; 195(1): 1-10. doi: 10.1016/s10727515(02)01197-3.

18. Metz CM, Hak DJ, Goulet JA, Williams D. Pelvic fracture patterns and their corresponding angiographic sources of hemorrhage. Orthop Clin North Am 2004; 35(4): 431-7. doi: 10.1016/j.ocl.2004.06.002.

19. Cestero RF, Plurad D, Green D, Inaba K, Putty B, Benfield $\mathrm{R}$, et al. Iliac artery injuries and pelvic fractures: a national trauma database analysis of associated injuries and outcomes. J Trauma 2009; 67(4): 715-8. doi: 10.1097/ TA.0b013e3181af6e88.

20. Corwin MT, Sheen L, Kuramoto A, Lamba R, Parthasarathy $\mathrm{S}$, Holmes JF. Utilization of a clinical prediction rule for abdominal-pelvic CT scans in patients with blunt abdominal trauma. Emerg Radiol 2014; 21(6): 571-6. doi: 10.1007/s10140-014-1233-1. 